\title{
(6) OPEN ACCESS \\ Which factors differentiate athletes with hip/groin pain from those without? A systematic review with meta-analysis
}

\author{
Andrea B Mosler, ${ }^{1,2}$ Rintje Agricola, ${ }^{3}$ Adam Weir, ${ }^{4}$ Per Hölmich, ${ }^{4,5}$ Kay M Crossley ${ }^{2,6}$
}

\begin{abstract}
- Additional material is published online only. To view please visit the journal online (http://dx.doi.org/10.1136/ bjsports-2015-094602).

${ }^{1}$ Rehabilitation Department, Aspetar Orthopaedic and Sports Medicine Hospital, Doha, Qatar

${ }^{2}$ School of Health and Rehabilitation Sciences, University of Queensland, Brisbane, Australia ${ }^{3}$ Department of Orthopaedics, Erasmus University Medical Centre, Rotterdam, the Netherlands

${ }^{4}$ Sports Groin Pain Centre Aspetar Orthopaedic and Sports Medicine Hospital, Doha, Qatar

${ }^{5}$ Arthroscopic Center Amager, SORC-C, Copenhagen University Hospital, Amager-Hvidovre, Denmark ${ }^{6}$ School of Allied Health, La Trobe University, Victoria, Australia
\end{abstract}

\section{Correspondence to} Professor Kay M Crossley, School of Allied Health, College of Science, Health and Engineering, La Trobe University, Bundoora, Victoria 3068, Australia;

k.crossley@latrobe.edu.au

Accepted 4 April 2015

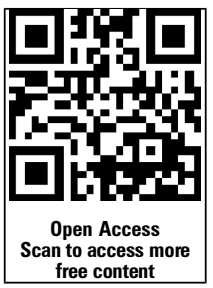

CrossMark

To cite: Mosler $A B$, Agricola R, Weir $A$, et al. $B r$ J Sports Med 2015;49:810.
ABSTRACT

Background Hip and groin injuries are common in many sports. Understanding the factors differentiating athletes with hip/groin pain from those without these injuries could facilitate management and prevention. Objective Conduct a systematic review and metaanalysis of the literature on factors differentiating athletes with and without hip/groin pain.

Methods The review was registered as PROSPERO CRD42014007416 and a comprehensive, systematic search was conducted in June 2014. Inclusion criteria were: cross-sectional, cohort or case-control study designs of $n>10$ that examined outcome measures differentiating athletes with and without hip/groin pain. Two authors independently screened search results, assessed study quality, and performed data extraction. Methodological heterogeneity was determined and data pooled for meta-analysis when appropriate. A best evidence synthesis was performed on the remaining outcome measures.

Results of 2251 titles identified, 17 articles were included of which 10 were high quality. Sixty two different outcome measures were examined, 8 underwent meta-analysis. Pooled data showed strong evidence that athletes with hip/groin pain demonstrated: pain and lower strength on the adductor squeeze test, reduced range of motion in hip internal rotation and bent knee fall out; however, hip external rotation range was equivalent to controls. Strong evidence was found that lower patient-reported outcome (PRO) scores, altered trunk muscle function, and moderate evidence of bone oedema and secondary cleft sign were associated with hip/groin pain.

Conclusions PROs, pain and reduced strength on the adductor squeeze test, reduced range of motion in internal rotation and bent knee fall out are the outcome measures that best differentiate athletes with hip/groin pain from those without this pain.

\section{INTRODUCTION}

Hip and groin pain is problematic for athletes, particularly in sports involving high loads of running, change of direction and kicking. Groin pain is the third most common injury in both soccer and Australian Rules football, accounting for $4-16 \%$ of all injuries sustained per season. ${ }^{12}$ It is also frequent in other football codes, such as Rugby League, $^{3}$ Gaelic Football ${ }^{4}{ }^{5}$ and American Football, ${ }^{6}$ as well as ice hockey. ${ }^{7}$ The aetiology is multifactorial, with coexisting pathological processes occurring in different tissues. ${ }^{8-11}$ Varying approaches have been recommended to systematically examine and diagnose groin pain in an athlete. ${ }^{11-13}$ While the reliability of the tests used in these approaches has been examined, ${ }^{14-16}$ there remains a lack of consensus on the terminology and diagnostic categories used.

Intrinsic risk factors for hip/groin pain in athletes have been prospectively studied. ${ }^{3}{ }^{17-23}$ Two systematic reviews identified only past history of injury and lower adductor strength as risk factors, while there is conflicting evidence for reduced hip range of motion. ${ }^{4} 24$ Injury prevention programmes aimed at reducing the incidence of groin pain by addressing these potentially modifiable risk factors have had limited efficacy. ${ }^{25-28} \mathrm{Hip}$ and groin pain still has a high incidence and recurrence rate. ${ }^{17} 23$ Therefore, it seems that we do not yet fully understand these injuries and further research is required to assist in the understanding of injury mechanisms, and factors contributing to the development of hip/ groin pain.

Injury prevention and management programmes may be enhanced by knowledge of the factors differentiating athletes with and without hip/groin pain. Previous case-control and cohort studies have examined the relationship between hip/ groin pain, and various clinical and radiological features. ${ }^{5}$ 15-17 22 29-42 A systematic evaluation of this literature may assist in the management and prevention of this common athletic injury.

This study aimed to systematically review the literature examining the factors differentiating athletes with and without hip/groin pain.

\section{METHODS}

This review followed the PRISMA guidelines and the protocol was registered on the PROSPERO International prospective register for systematic reviews website (http://www.crd.york.ac.uk/PROSPERO) on 9 April 2014, with the following registration number: CRD42014007416.

\section{Eligibility criteria}

Inclusion criteria were (1) case-control, cohort and cross-sectional study designs, and (2) study of at least one factor differentiating between athletic subjects with hip/groin pain and those without. Hip/ groin pain participants were defined as those identified with having pain in the hip and groin region, and encompassed the many different terminologies used to describe athletic groin pain such as osteitis pubis, long-standing groin pain, pubalgia, adductorrelated groin pain, and hip joint pain. Athletic populations included people who participated in any of the sports included under the MESH term 'sports' plus marathon running. No restrictions 
were placed on the duration of participant symptoms. In order to reduce the potential risk of bias, a minimum number of 10 cases of hip/groin pain and control subjects were required. Studies written in English, Dutch, German, Italian, French or Spanish were included. Studies without a control group were excluded from the review.

\section{Search strategy}

A comprehensive, systematic literature search was conducted on 20 June 2014, using the following electronic databases with no date restrictions (1) EMBASE.com (2) MEDLINE (OvidSP) (3) Cochrane (4) Web-of-science (5) Scopus (6) Cinahl (7) PubMed publisher (8) Google Scholar and (9) Sport Discus. The complete electronic search strategy is available in online supplementary material A. The literature search was assisted by a biomedical information specialist (W.M. Bramer, Erasmus University). The following key words were used for the search with differing combinations: 'hip', 'inguinal', 'groin', 'pubalgia', 'pain', 'sport', 'team sport', 'sport injury', 'sports medicine', 'athlete', 'athletic performance' plus the MESH term 'sports' plus marathon running. Search strategies were adapted as required for each specific database

All potential references were imported into Endnote X4 (Thomson Reuters, Carlsbad, California, USA) and duplicates removed. Title and abstracts were independently screened for eligibility by two authors (ABM and RA). The full text of each eligible published study was then independently examined given the inclusion criteria and reference lists manually searched to identify further relevant articles.

\section{Quality appraisal}

Two reviewers (ABM and RA) independently conducted methodological quality assessment on each included article using the modified Downs and Black scale (see online supplementary B), which is appropriate for cohort and case-control study designs. The Downs and Black scale is reliable $\mathrm{e}^{43}$ and the modified version used in this study had a maximum score of $16 .^{44} 45$ The methodological quality of each article was stratified, as in previous reviews, ${ }^{45}$ with a total score $\geq 12$ deemed to be high quality, 10 or 11 to be moderate quality, and low quality if the score was $\leq 9$. Disagreements in initial ratings of methodological quality assessment were discussed between the two reviewers (ABM, RA) and if required, a third reviewer (KMC) was consulted to reach consensus.

\section{Data extraction}

All data from the included studies were independently extracted, collated by consensus agreement, and entered into a predefined Excel spread sheet by two reviewers (ABM, RA). If sufficient data were not reported in the published article or online supplementary material provided, the corresponding author was contacted to request further data.

Study data were subdivided into the following categories: patient reported outcome (PRO) measures, pain provocation tests, range of motion, strength, trunk muscle function, radiological measures, and other outcome measures.

\section{Data synthesis and analysis}

Data extraction of the included studies was conducted with means and SDs calculated for continuous data for the hip/groin and control participants separately. If data were not presented in a manner enabling extraction, the corresponding author was contacted to obtain the raw data. Where separate data were presented for both legs of control subjects; an average mean and $\mathrm{SD}$ was calculated. For the case groups, data from the symptomatic leg were used if available or a mean (SD) of data from both legs calculated if participants had bilateral symptoms or if the symptomatic leg could not be determined. If more than one method of measurement was used for a single outcome measure, the data were extracted from the method used most consistently between studies and/or determined to be most reliable.

Methodological and clinical heterogeneity was evaluated for all outcome measures and data pooled for meta-analysis as appropriate. The software package from Review Manager (RevMan) Version 5.3, Copenhagen: The Nordic Cochrane Centre, The Cochrane Collaboration, 2014, was used to conduct the meta-analysis. Standardised mean differences (SMD) with 95\% CIs were calculated for outcome measures of continuous data and random effects models were used for each meta-analysis. The magnitude of the effect size of the pooled SMD was interpreted as large if SMD $\geq 0.8$; moderate if $0.5-$ 0.8 ; weak if $0.2-0.5$, and no effect determined if $\mathrm{SMD} \leq 0.2 .{ }^{46}$

Statistical heterogeneity of the pooled data was examined using the $\mathrm{I}^{2}$ statistic. Sensitivity analysis was conducted by examining the forest plots of the pooled data following omission of the data from each study, one by one.

For dichotomous data, an OR was calculated for the association between a positive test and the presence of hip and groin pain, and data pooled if methodological homogeneity was determined. Effect sizes for the OR were defined as follows: small effect $\mathrm{OR}=1-1.25$, medium effect $\mathrm{OR}=1.25-2$ and large effect $\mathrm{OR} \geq 2 .{ }^{47}$

For outcome measures with methodological or clinical heterogeneity, qualitative data synthesis and analysis was performed. For both quantitative and qualitative data synthesis, a level of evidence was assigned to each outcome according to the recommendations proposed by van Tulder et al. ${ }^{48}$

\section{RESULTS}

\section{Literature search}

The electronic search identified 5269 records and following removal of duplicates, the titles and abstracts of 2251 articles were screened. The full text of 41 articles were retrieved and assessed for eligibility against the inclusion criteria. Two articles were added following citation checking. ${ }^{36} 37$ After reviewing the full text of 43 articles, 26 articles were excluded and the remaining 17 articles ${ }^{5} 15 \quad 16 \quad 30-33 \quad 35-40 \quad 50-53$ were included for full review and data synthesis (figure 1).

\section{Methodological quality}

Two reviewers (ABM and RA) initially disagreed upon 21\% of the items of the 17 included studies (54 of 255 items). However, all initial disagreements were discussed and consensus reached on a final score for each paper, using the assistance of a third reviewer (KMC) where required. The methodological quality scores ranged from 8 to 15 out of maximum possible score of 16 , with the average score being 12 (see online supplementary table S1). Ten of the included studies were of high quality, 6 were of moderate quality and only 1 low quality study was included for final data synthesis. Three studies scored positively on item 14 (sample size calculation) while 7 studies reported blinding of assessors with respect to the presence of hip/groin pain of the subjects (item 8). 
Figure 1 Flow diagram for search results and study selection.

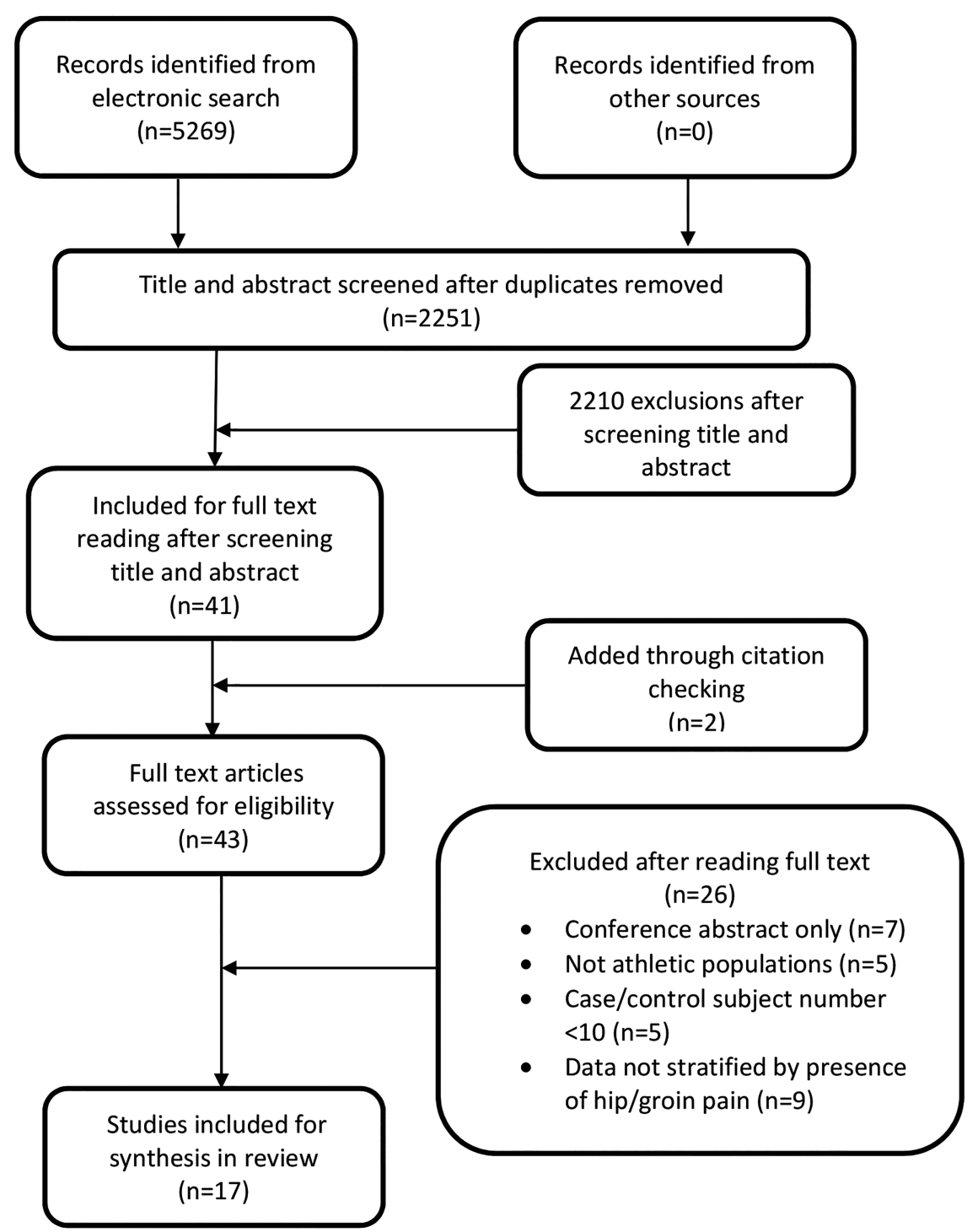

\section{Characteristics of included studies}

Table 1 presents the full characteristics of the included studies. Data extraction was performed on all 17 of the included studies and a detailed description of the studies is presented regarding authors, year of publication, study design, participants (case and control), diagnosis, symptom duration, outcome measure(s) examined, method of measurement, differences between case and control.

\section{Factors differentiating athletes with and without hip/groin pain}

Patient reported outcome measures

Several studies presented data from PROs, completed by both control and hip/groin pain athletes. ${ }^{5} 30313652$ None used identical PROs, but three high-quality studies assessed aspects of pain using a Likert scale. ${ }^{30} 3136$ The Copenhagen hip and groin outcome score (HAGOS) was used in one high-quality study, ${ }^{5}$ while another high-quality study ${ }^{52}$ used both the short form (SF)-12, and the Hip Disability and Osteoarthritis Outcome Score (HOOS). The results of the PROs are summarised in table 2. All PROs were able to differentiate between athletes with and without hip/groin pain, apart from the mental component summary (MCS) of the SF-12. Synthesising these findings, there is strong evidence that PROs can be used to differentiate athletes with and without hip/groin pain.
Pain provocation tests

Five studies examined the difference between athletes with and without hip/groin pain in response to various pain provocation tests. $^{16} 30 \quad 353653$ The pain on adductor squeeze testing was recorded by 3 high-quality studies using the same methodology (supine, resisted adduction at the medial knee with hips at $45^{\circ}$ flexion, and knees flexed $\left.90^{\circ}\right){ }^{16} 3053$ One of these studies ${ }^{30}$ reported significantly greater pain experienced during the squeeze test in the hip/groin pain group $(p<0.001)$. However, information on the number of groin pain athletes who experienced pain with the squeeze test was not presented; therefore, the data from this study could not be pooled. Data pooling from the other 2 studies revealed a greater chance of being in the hip/groin pain group if participants experienced pain during the squeeze test with a large effect size; OR $=4.31 \quad(95 \% \mathrm{CI}$ 1.86 to 10 ) figure 2 . There is, therefore, strong evidence that pain on the adductor squeeze test differentiates athletes with hip/groin pain from those without pain.

The ORs for the other pain provocation tests examined in single studies are: single adductor test (supine, leg straight and resisted adduction at the ankle): ${ }^{16} \mathrm{OR}=4.03(1.21-13.45)$, bilateral adductor test (resisted bilateral adduction while athlete holds both legs off the bed in $30^{\circ}$ hip flexion): ${ }^{16} \mathrm{OR}=24.76(5.35-$ 114.6), active straight leg raise test: ${ }^{36} \mathrm{OR}=56.64$ (3.27-980.14), 
Table 1 Characteristics of included Studies (figures displayed as mean \pm SD unless otherwise stated)

\begin{tabular}{|c|c|c|c|c|c|c|c|c|c|}
\hline \multirow{2}{*}{$\begin{array}{l}\text { Authors, study } \\
\text { design }\end{array}$} & \multirow[b]{2}{*}{ level**; type of sporting activity } & \multicolumn{3}{|c|}{ Hip/groin pain } & \multicolumn{3}{|c|}{ Control } & \multirow{2}{*}{$\begin{array}{l}\text { Diagnosis; duration } \\
\text { of symptoms }\end{array}$} & \multirow{2}{*}{$\begin{array}{l}\text { Comparisons between case and control; } \\
\text { SMD, MD or OR ( } 95 \% \text { confidence intervals) }\end{array}$} \\
\hline & & n & Sex & Age & $\mathbf{n}$ & Sex & Age & & \\
\hline \multicolumn{10}{|l|}{ Pain provocation tests } \\
\hline $\begin{array}{l}\text { Jansen et al } \\
\text { Case-control }\end{array}$ & $\begin{array}{l}\text { A, case }=\text { soccer }(75 \%) \text {, running }(12 \%) \text {, other }(13 \%) \text {; } \\
\text { control=soccer }(65 \%) \text {, running }(13 \%) \text {, other }(22 \%)\end{array}$ & 42 & M & $26 \pm 8$ & 23 & M & $24 \pm 5$ & ARGP $>6$ weeks & ADD squeeze test ${ }^{*}$, active straight leg raise* \\
\hline $\begin{array}{l}\text { Taylor et a } f^{53} \\
\text { Cross-sectional cohort }\end{array}$ & P, AFL & 15 & M & $17 \pm 1$ & 218 & M & $16 \pm 1$ & Hip or groin injury, ND & ADD squeeze $O R=3.47(0.9-12.9)$ \\
\hline $\begin{array}{l}\text { Mens et a } a^{36} \\
\text { Case-control }\end{array}$ & $\begin{array}{l}\text { A, case }=\operatorname{soccer}(70 \%) \text {, tennis }(11 \%) \text {, other }(19 \%) \text {, } \\
\text { control= soccer }(70 \%) \text {, tennis }(9 \%) \text {, other }(21 \%)\end{array}$ & $\begin{array}{r}38 \\
6\end{array}$ & $\begin{array}{l}M \\
F\end{array}$ & $\begin{array}{l}31 \\
28-35 \dagger\end{array}$ & $\begin{array}{l}38 \\
6\end{array}$ & $\begin{array}{l}M \\
F\end{array}$ & $\begin{array}{l}32 \\
30-35+\end{array}$ & Groin pain $>1$ month & $\begin{array}{l}\text { Active straight leg raise } O R=56.64(3.3-980.1) \text {, pelvic belt } \\
O R=187.21(10.8-3257.8)\end{array}$ \\
\hline $\begin{array}{l}\text { Verrall et al }{ }^{16} \\
\text { Cross-sectional cohort }\end{array}$ & P, AFL & 47 & M & ND & 42 & M & ND & $\begin{array}{l}\text { Chronic groin injury } \\
>6 \text { weeks }\end{array}$ & $\begin{array}{l}\text { ADD squeeze } O R=5.02(1.7-15.1) \text {, single adductor } \\
O R=4.03(1.2-13.5) \text {, bilateral adductor } \mathrm{OR}=24.76(5.4-114.6)\end{array}$ \\
\hline \multicolumn{10}{|l|}{ Range of motion } \\
\hline $\begin{array}{l}\text { Nevin and Delahunt } \\
\text { Case-control }\end{array}$ & ND, Gaelic football & 18 & M & $24 \pm 3$ & 18 & M & $24 \pm 4$ & ARGP $>6$ weeks & $\begin{array}{l}\mathrm{IR}=-0.82(-1.5 \text { to }-0.1)^{*} ; \mathrm{SMD} \\
\mathrm{ER}=-0.57(-1.2-0.1)^{*} ; \mathrm{SMD} \\
\mathrm{BKFO}=0.9(0.2-1.6)^{*} ; \text { SMD }\end{array}$ \\
\hline $\begin{array}{l}\text { Taylor et a }\left.\right|^{53} \\
\text { Cross-sectional cohort }\end{array}$ & $\mathrm{P}, \mathrm{AFL}$ & 15 & M & $17 \pm 1$ & 218 & M & $16 \pm 1$ & Hip or groin injury, ND & $\begin{array}{l}\mathrm{IR}=-0.37(-0.9-0.2)^{*} ; \mathrm{SMD} \\
\mathrm{ER}=0.06(-0.5,0.6) ; \mathrm{SMD}\end{array}$ \\
\hline $\begin{array}{l}\text { Malliaras et al }{ }^{15} \\
\text { Case-control }\end{array}$ & P, AFL & 10 & M & $17 \pm 2$ & 19 & M & $17 \pm 1$ & ARGP $>6$ weeks & $\begin{array}{l}\mathrm{IR}=-0.02(-0.8-0.8) ; \mathrm{SMD} \\
\mathrm{BKFO}=0.56(-0.2-1.4)^{*} ; \mathrm{SMD} \\
\mathrm{ER}=-0.17(-0.9-0.6) ; \text { SMD }\end{array}$ \\
\hline $\begin{array}{l}\text { Verrall et } a^{\beta 3} \\
\text { Cross-sectional cohort }\end{array}$ & P, AFL & 47 & M & ND & 42 & M & ND & $\begin{array}{l}\text { Chronic groin injury } \\
>6 \text { weeks }\end{array}$ & $\begin{array}{l}\mathrm{IR}=-0.39(-0.8-0) ; \mathrm{SMD} \\
\mathrm{ER}=-2.55(-4.8-0.3) ; \mathrm{MD} \text { (degrees) }\end{array}$ \\
\hline $\begin{array}{l}\text { Siebenrock et a }\left.\right|^{35} \\
\text { Cross-sectional cohort }\end{array}$ & P, ice hockey & 15 & M & $\begin{array}{l}19 \\
11-36+ \\
\end{array}$ & 62 & M & $\begin{array}{l}14 \\
9-34 \dagger\end{array}$ & $\begin{array}{l}\text { Hip pain within past } \\
6 \text { months }\end{array}$ & $\mathrm{IR}=-0.85(-1.4 \text { to }-0.3)^{*} ; \mathrm{SMD}$ \\
\hline \multicolumn{10}{|l|}{ Strength } \\
\hline $\begin{array}{l}\text { Malliaras et al } \\
\text { Case-control }\end{array}$ & P, AFL & 10 & M & $17 \pm 2$ & 19 & M & $17 \pm 1$ & ARGP $>6$ weeks & $\begin{array}{l}\text { ADD squeeze strength }=-0.73(-1.5-0.1)^{*} ; \text { SMD } \\
\text { ABD strength }=-0.25(-2-1.9) ; \mathrm{MD}(\mathrm{N})\end{array}$ \\
\hline $\begin{array}{l}\text { Mens et a/ } \\
\text { Case-control }\end{array}$ & $\begin{array}{l}\text { A, case }=\text { soccer }(70 \%) \text {, tennis }(11 \%) \text {, other }(19 \%) \text {, } \\
\text { control= soccer }(70 \%) \text {, tennis }(9 \%) \text {, other }(21 \%)\end{array}$ & $\begin{array}{r}38 \\
6\end{array}$ & $\begin{array}{l}M \\
F\end{array}$ & $\begin{array}{l}31 \\
28-35+\end{array}$ & $\begin{array}{l}38 \\
6\end{array}$ & $\begin{array}{l}M \\
F\end{array}$ & $\begin{array}{l}32 \\
30-35 t\end{array}$ & Groin pain $>1$ month & ADD squeeze strength $=-2.31(-2.9 \text { to }-1.8)^{*} ; \mathrm{SMD}$ \\
\hline $\begin{array}{l}\text { Nevin and Delahunt }{ }^{5} \\
\text { Case-control }\end{array}$ & ND, Gaelic football & 18 & M & $24 \pm 3$ & 18 & M & $24 \pm 4$ & ARGP $>6$ weeks & ADD squeeze strength $=-2.06(-2.9 \text { to }-1.2)^{*} ; \mathrm{SMD}$ \\
\hline $\begin{array}{l}\text { Jansen et al } \\
\text { Case-control }\end{array}$ & $\begin{array}{l}\text { A, case }=\text { soccer }(75 \%) \text {, running }(12 \%) \text {, other }(13 \%) \text {; } \\
\text { control=soccer }(65 \%) \text {, running }(13 \%) \text {, other }(22 \%)\end{array}$ & 42 & M & $26 \pm 8$ & 23 & M & $24 \pm 5$ & ARGP $>6$ weeks & ADD squeeze strength $=-0.54(-1.06$ to -0.02$) *$; SMD \\
\hline $\begin{array}{l}\text { Mohammad et al } \\
\text { Case-control }\end{array}$ & ND, soccer & 20 & M & $20 \pm 4$ & 20 & M & $21 \pm 3$ & Osteitis pubis, ND & $\begin{array}{l}\mathrm{ABD}=-8.52(-24.5-7.5), \mathrm{MD}(\mathrm{Nm} / \mathrm{kg}) \\
\mathrm{ADD}=-0.24(-17.4-7.6), \mathrm{MD}(\mathrm{Nm} / \mathrm{kg}) \\
\mathrm{Flex}=38.85(21.4-56.3)^{*}, \mathrm{MD}(\mathrm{Nm} / \mathrm{kg}) \\
\text { Ext=11.79 }(-1.5-25), \mathrm{MD}(\mathrm{Nm} / \mathrm{kg}) \\
\text { Ratios; ADD/ABD=0.06 }(-0.5-0.6), \text { Flex/Ext }=0.18(-0.8-1.2)^{*}\end{array}$ \\
\hline
\end{tabular}




\section{Table 1 Continued}

\begin{tabular}{|c|c|c|c|c|c|c|c|c|c|}
\hline \multirow{2}{*}{$\begin{array}{l}\text { Authors, study } \\
\text { design }\end{array}$} & \multirow[b]{2}{*}{ level ${ }^{* *}$; type of sporting activity } & \multicolumn{3}{|c|}{ Hip/groin pain } & \multicolumn{3}{|c|}{ Control } & \multirow{2}{*}{$\begin{array}{l}\text { Diagnosis; duration } \\
\text { of symptoms }\end{array}$} & \multirow{2}{*}{$\begin{array}{l}\text { Comparisons between case and control; } \\
\text { SMD, MD or OR ( } 95 \% \text { confidence intervals) }\end{array}$} \\
\hline & & $\mathrm{n}$ & Sex & Age & $\mathrm{n}$ & Sex & Age & & \\
\hline \multicolumn{10}{|l|}{ Trunk muscle function } \\
\hline $\begin{array}{l}\text { Cowan et a }\left.\right|^{31} \\
\text { Case-control }\end{array}$ & $A$ and $P, A F L$ & 10 & M & $26 \pm 7$ & 12 & M & $25 \pm 6$ & ARGP $>6$ weeks & $\begin{array}{l}\mathrm{TA}=-30(-38.4 \text { to }-21.6)^{*}, \mathrm{OE}=4(-6.1-14.1) \mathrm{MD} \text { 's }(\mathrm{ms}) \\
\mathrm{Ol}=-1.1(-7.9-5.7), \mathrm{RA}=3.5(-2.9-9.9) ; \mathrm{MD} \text { 's (ms) }\end{array}$ \\
\hline $\begin{array}{l}\text { Sayed Mohammad } \\
\text { et a }\left.\right|^{50} \\
\text { Case-control }\end{array}$ & ND, soccer & 25 & M & $20 \pm 4$ & 25 & M & $21 \pm 3$ & Osteitis pubis, ND & $\begin{array}{l}\text { Abdominals conc }=1.78(-9-12.5) \text {, ecc }=-37.24(-44.5 \text { to }-30)^{*} ; \mathrm{MD}^{\prime} \mathrm{s}(\mathrm{Nm} / \mathrm{kg}) \\
\text { back conc }=-81.99(-96.9 \text { to }-67.1)^{*} \text {, ecc }=9.24(-1.8-20.3) ; \mathrm{MD}^{\prime} \mathrm{s}(\mathrm{Nm} / \mathrm{kg}) ; \\
\text { Ratio abdominals/back conc }=0.41(-0.1-0.9)^{*} \text {, ecc }=-0.28(-0.7-0.1)\end{array}$ \\
\hline $\begin{array}{l}\text { Jansen et a } a^{30} \\
\text { Case-control }\end{array}$ & $\begin{array}{l}\text { A, case }=\text { soccer }(75 \%) \text {, running }(12 \%) \text {, other }(13 \%) \text {; } \\
\text { control }=\text { soccer }(65 \%) \text {, running }(13 \%) \text {, other }(22 \%)\end{array}$ & 42 & M & $26 \pm 8$ & 23 & M & $24 \pm 5$ & ARGP $>6$ weeks & $\begin{array}{l}\text { TA thinner at rest in groin pain group* no significant difference; Ol at rest, TA or OI } \\
\text { with tasks }\end{array}$ \\
\hline \multicolumn{10}{|l|}{ Radiological } \\
\hline $\begin{array}{l}\text { Besjakov et al } \\
\text { Case-control }\end{array}$ & case $=N D$, soccer $(85 \%)$, other $(15 \%)$; control=ND,ND & 20 & M & $\begin{array}{l}26 \\
19-35 \dagger\end{array}$ & 20 & M & age-matched & Groin pain, $>3$ months & $\begin{array}{l}\text { Case; 9/20 slight, 9/20 intermediate, } 2 / 20 \text { advanced abnormalities. } \\
\text { Control; } 3 / 20 \text { none, } 17 / 20 \text { slight abnormalities of pubic bone on } X \text {-ray }\end{array}$ \\
\hline $\begin{array}{l}\text { Paajanen et a/ }{ }^{40} \\
\text { Case-control }\end{array}$ & $\begin{array}{l}\text { ND, case }=\text { soccer }(81 \%) \text {, other }(19 \%) \text {, control=soccer } \\
(50 \%) \text {, ice hockey }(50 \%)\end{array}$ & $\begin{array}{r}14 \\
2\end{array}$ & $\begin{array}{l}M \\
F\end{array}$ & $\begin{array}{l}30 \pm 8 \\
22 \pm 11\end{array}$ & 20 & M & $23 \pm 4$ & $\begin{array}{l}\text { Osteitis pubis } \\
>3 \text { months }\end{array}$ & Pubic bone oedema OR=8.08 (0.9-74.6) \\
\hline $\begin{array}{l}\text { Verrall et } a^{32} \\
\text { Case-control }\end{array}$ & P, AFL players and umpires & 52 & M & ND & 54 & M & ND & Osteitis pubis, ND & Pubic bone oedema $\mathrm{OR}=8.10(2.8-23.5)$ \\
\hline $\begin{array}{l}\text { Cunningham et a } a^{38} \\
\text { Case-control }\end{array}$ & $\begin{array}{l}\text { case }=A \text { and } P \text {, soccer; control=ND, soccer }(50 \%) \text {, rowers } \\
(50 \%)\end{array}$ & $\begin{array}{r}95 \\
5\end{array}$ & $\begin{array}{l}M \\
F\end{array}$ & $\begin{array}{l}27 \\
17-38+\end{array}$ & 100 & ND & $\begin{array}{l}23 \\
18-28+\end{array}$ & $\begin{array}{l}\text { Osteitis pubis, Mean of } \\
3 \text { months }\end{array}$ & $\begin{array}{l}\text { Pubic bone oedema } O R=1936(111-33733) \\
\text { Secondary cleft sign } O R=1423(83-24384)\end{array}$ \\
\hline $\begin{array}{l}\text { Brennan et } a^{37} \\
\text { Case-control }\end{array}$ & $\begin{array}{l}\text { case }=N D \text {, soccer }(83 \%) \text {, and rugby }(17 \%) \text {; control=A, } \\
\text { rowers }\end{array}$ & 18 & M & $\begin{array}{l}24 \\
19-32 \dagger\end{array}$ & 70 & M & $\begin{array}{l}24 \\
17-34 \dagger\end{array}$ & $\begin{array}{l}\text { Groin injury, Mean of } \\
3 \text { months }\end{array}$ & Secondary cleft sign $O R=271(14-5122)$ \\
\hline $\begin{array}{l}\text { Siebenrock et } a^{35} \\
\text { Cross-sectional cohort }\end{array}$ & P, ice hockey & 15 & M & $\begin{array}{l}19 \\
11-36 t\end{array}$ & 62 & M & $\begin{array}{l}14 \\
9-34 \dagger\end{array}$ & $\begin{array}{l}\text { Hip pain within past } 6 \\
\text { months }\end{array}$ & 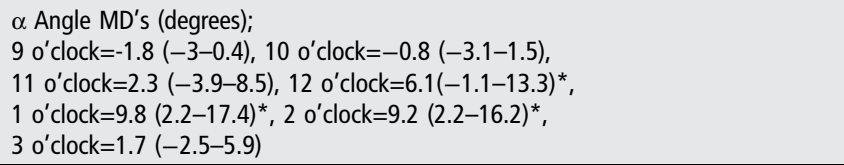 \\
\hline
\end{tabular}

\section{Other}

Bedi et $\left.a\right|^{52}$

ND, 'physically active' subjects

$\begin{array}{llllll}10 & \text { M } & 23 \pm 6 & 19 & \text { M } & 22 \pm 3\end{array}$

FAl, ND

COMP $=48.00 \mu g / L(-9.1-105.1)^{*} ; \mathrm{MD}$

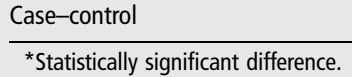

tRange.

**Level: A, amateur; AFL, Australian Rules Football; ND, not described; P, professional//lite.

ABD, Hip abduction; ADD, Hip adduction; ARGP, adductor related groin pain; BKFO, bent knee fall out; COMP, Cartilage oligomeric matrix protein; CRP, C reactive protein; ER, hip external rotation; Ext, hip extension; F, Female; FAI, femoroacetabular impingement; Flex, hip flexion; IR, hip internal rotation; M, Male; MD, mean difference; N, Newton; OE, obliquus externus; OI, obliquus internus; RA, rectus abdominus; ROM, range of motion; SMD, standardised mean difference;

TA, transversus abdominus; US, ultrasound. 


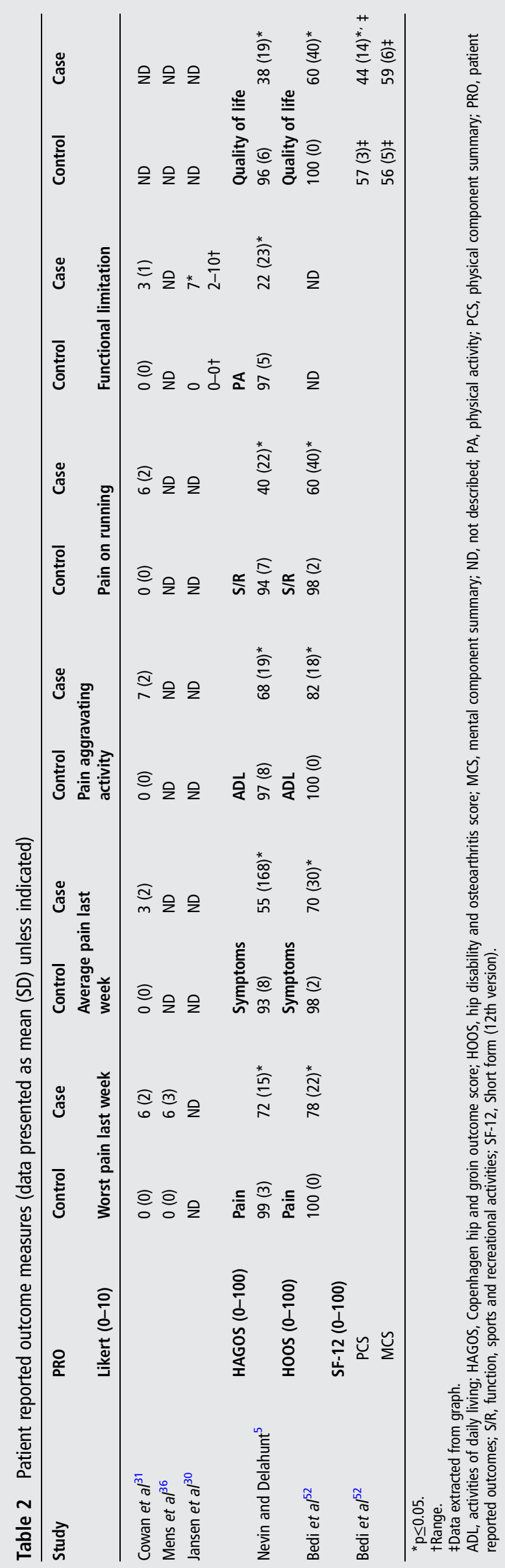

pelvic belt test: ${ }^{36} \mathrm{OR}=187.21 \quad(3.27-980.14)$, impingement test: ${ }^{35} \mathrm{OR}=50.62(11.3-226.73)$.

The active straight leg raise test was also examined in an additional high-quality study, ${ }^{30}$ but despite the authors finding a statistically significant difference between the control and hip/ groin pain subjects for this test $(p=0.001)$, the mean of the control group was $0(0-0)$ and for the hip/groin pain group this was also $0(0-4)$, consequently an OR could not be calculated. Despite the high-diagnostic ORs for the single adductor, bilateral adductor, active straight leg raise, pelvic belt, and impingement tests, the results demonstrated in single studies show that there is currently limited evidence that these tests differentiate between hip/groin pain athletes from those without pain.

\section{Range of motion}

Five studies examined hip range of motion, including the variables of hip internal and external rotation, and bent knee fall out. $^{5} 15333553$

Hip internal rotation (IR) was measured in prone with the hip in neutral flexion/extension in 3 high-quality studies (figure 3). ${ }^{515} 53$ The meta-analysis revealed strong evidence that hip IR range in prone is less in athletes with hip and groin pain $\mathrm{SMD}=0.42(0.01-0.83)$ than those without pain. The difference in range between the two groups equated to an average of $3.7^{\circ}\left(1.1-6.3^{\circ}\right)$ of reduced hip IR in the athletes with pain, which represents a weak effect.

Hip IR was measured in supine with the hip and knee at $90^{\circ}$ flexion in 2 moderate quality studies. ${ }^{33}$ Meta-analysis provided moderate evidence that hip IR range measured in supine was less in athletes with hip/groin pain; $\mathrm{SMD}=0.58(0.14-1.01)$ figure 4 . This moderate effect equated to an average of $3.83^{\circ}$ $\left(0.31-7.75^{\circ}\right)$ of reduced hip IR in the athletes with pain.

External rotation (ER) was measured in supine with the hip in neutral flexion/extension in three high-quality studies, ${ }^{5} 1553$ and in supine with the hip in $90^{\circ}$ flexion in 1 moderate quality study. ${ }^{33}$ The data was pooled for the three studies with neutral flexion/extension (figure 5). There was strong evidence that hip ER range of motion did not differentiate hip/groin pain athletes from those without pain; $S M D=0.18(-0.55$ to 0.19$)$. In the single study ${ }^{33}$ with hip ER measured in $90^{\circ}$ flexion, a weak effect size was present between the hip/groin pain group and control groups; $\mathrm{SMD}=0.47(0.04-0.89)$. This difference in range equates to $2.55^{\circ}\left(0.31-4.79^{\circ}\right)$, and provided limited evidence that reduced hip ER range measured in $90^{\circ}$ flexion was associated with hip/groin pain in athletes.

Bent knee fall out (BKFO) is a combined movement of hip flexion, abduction and external rotation, and was examined in two high-quality studies, ${ }^{5} 15$ Meta-analysis was possible as identical measurement methods were used. There was strong evidence that a higher score on bent knee fall out, representing reduced range of motion for this test, differentiates athletes with hip/groin pain from those without pain; $\mathrm{SMD}=0.75(0.24-1.27)$ figure 6 . This moderate effect equates to $3.6 \mathrm{~cm}(1.3-5.8 \mathrm{~cm})$.

\section{Strength}

Strength on the adductor squeeze test measured at $45^{\circ}$ hip flexion, was examined quantitatively in five studies. 515303653 Data were available for four of these studies, and the pooled data (figure 7) demonstrated strong evidence that the presence of hip/groin pain was associated with less strength on adductor squeeze testing. The effect size was large; $\mathrm{SMD}=1.41(0.44-2.37)$.

The magnitude of the difference between the case and control groups varied between the studies as represented by the high statistical heterogeneity $\mathrm{I}^{2}=89 \%$. Separating the data into 


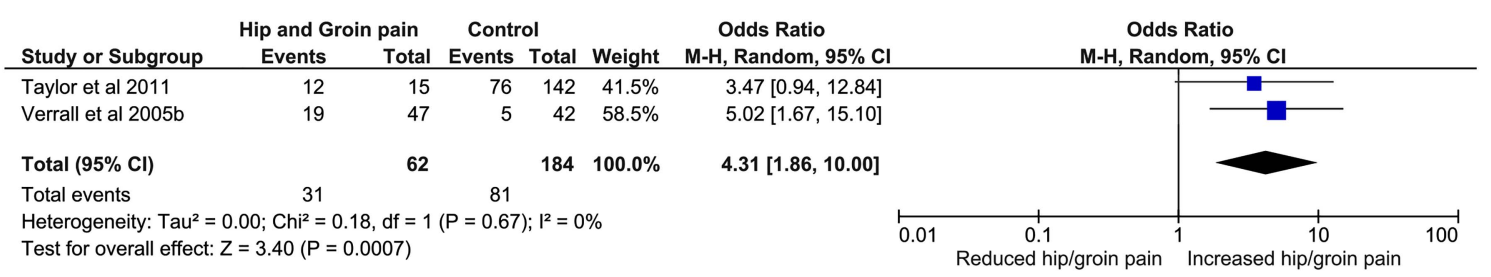

Figure 2 Forest plot demonstrating the odds ratio of pain with the adductor squeeze test.

common measurement units, the standardised mean difference between case and control equates to $49 \mathrm{~mm} \mathrm{Hg}(12-85 \mathrm{~mm} \mathrm{Hg})$ and $53 \mathrm{~N}(24-83 \mathrm{~N})$.

One high quality study also examined isometric abduction strength using a hand-held dynamometer, in supine with neutral hip flexion/extension. ${ }^{15}$ There was no difference between the hip/groin pain group and the controls for either leg $(\mathrm{p}=0.71-$ 0.84 ). Another high-quality study used an isokinetic dynamometer to compare hip abduction, adduction, flexion, and extension strength. ${ }^{51}$ In this study, only hip flexion strength was significantly different (higher) in the hip/groin pain group compared with controls $(p=0.028)$. Similarly, the ratio of hip flexors/extensors was significantly higher in the hip/groin pain group compared to the controls $(p=0.02)$. Therefore, there is limited evidence that when using an isokinetic dynamometer, hip flexion strength is greater in hip/groin pain participants than controls, but abduction, adduction and extension strength are similar.

\section{Trunk muscle function}

Trunk muscle function was measured in three high-quality studies, ${ }^{30} 3150$ Table 1. The methodologies and outcome measures were distinctly heterogeneous, precluding meta-analysis. The first study investigated electromyography activity of transversus abdominus, obliquus internus and externus and rectus femoris during an active straight leg raise task. ${ }^{31}$ The onset of transversus abdominus activity relative to rectus femoris was found to be delayed in the hip/groin pain group in comparison to controls $(p \leq 0.05)$. There was no significant difference between the onset timing for the other muscles relative to rectus femoris. Another study ${ }^{30}$ used ultrasound measurements to compare the thickness of tranversus abdominis and obliquus internus (as a measure of muscle recruitment capacity) at rest, and during both the active straight leg raise task and adductor squeeze test. The hip/groin pain participants had a significantly thinner transversus abdominis $(p=0.015)$ compared to controls when measured at rest, though no difference was found in obliquus internus thickness $(\mathrm{p} \geq 0.05)$. During both the active straight leg raise and adductor squeeze test, the thickness of both muscles was not significantly different between groups $(\mathrm{p} \geq 0.15)$.

Isokinetic dynamometry was used in another high-quality study to examine abdominal and back extensor muscle strength. ${ }^{50}$ A significantly lower concentric back $(p=0.001)$ and eccentric abdominal $(\mathrm{p}=0.005)$ muscle strength, and significantly greater concentric abdominal/back extensor ratio $(p=0.019)$ was found in the hip/groin pain group compared to the control group. There were no significant between-group differences found for eccentric back and concentric abdominal muscle strength $(\mathrm{p}>0.05)$, or eccentric abdominal/back extensor ratio $(p>0.05)$. Although these 3 studies examined different aspects of trunk muscle function, synthesis of these findings showed strong evidence that trunk muscle function is altered in athletes with hip/groin pain compared to athletes without pain.

\section{Radiological}

One low quality study used X-ray to examine the pubic symphyses of athletes with hip/groin pain and those without pain. ${ }^{39}$ A reliable grading system quantified the abnormalities, which were present in all the hip/groin pain subjects (9/20 slight, 9/20 intermediate, $2 / 20$ advanced). In contrast, the athletic control subjects had either no (3/20) or slight (17/20) abnormalities seen on X-ray. Another moderate quality study only reported the radiographic findings in the hip/groin pain subjects and not the control subjects. ${ }^{37}$ Synthesising the data on X-ray investigations of the pubic symphysis, there is currently limited evidence that X-ray findings differentiate athletes with hip/groin pain from athletes without pain.

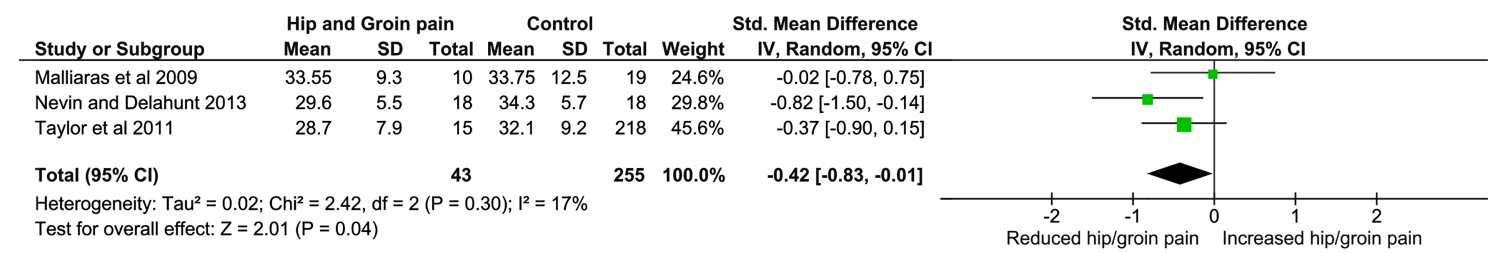

Figure 3 Forest plot: association between hip/groin pain and hip internal rotation range of motion measured with neutral flexion/extension.

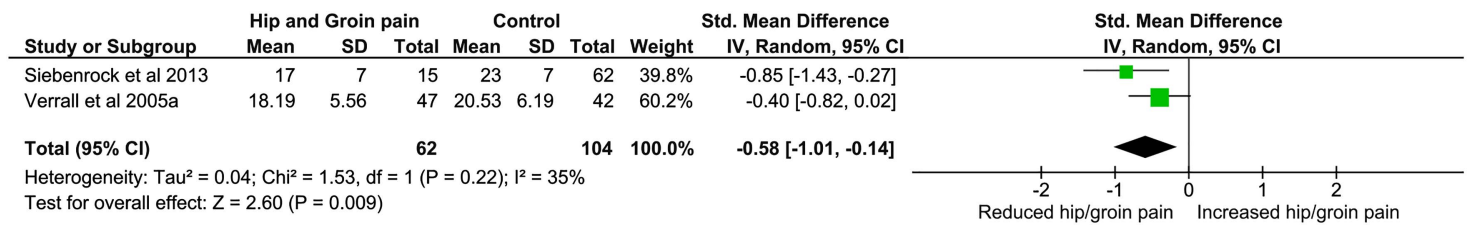

Figure 4 Forest plot: association between hip/groin pain and hip internal rotation range of motion measured with $90^{\circ}$ hip and knee flexion. 


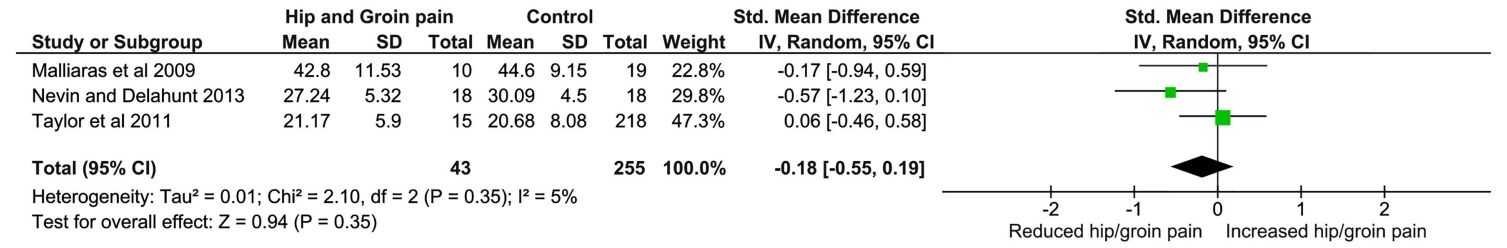

Figure 5 Forest plot: association between hip/groin pain and hip external rotation range of motion measured with neutral flexion/extension.

Three moderate quality studies examined pubic bone oedema using MRI in athletes with hip/groin pain and controls. ${ }^{32} 3840$ Dichotomous data for the presence or absence of bone oedema were extracted and pooled from these studies (figure 8). The results indicated that there were high odds that participants with bone oedema on MRI would be in the hip/groin pain group with a large effect size; OR=41.63 (1.6-1096.60). However, there was high heterogeneity demonstrated by this pooled result $\left(\mathrm{I}^{2}=88 \%\right)$, and significant sensitivity to the data from the study of Cunningham et $a l^{38}$ Figures 8 and 9. The removal of this study data resulted in an OR of 8.1 (3.1-21.2) for the presence of bone oedema in subjects with hip/groin pain, representing moderate evidence, with a large effect size, that bone oedema in the pubic symphysis differentiates athletes with hip/groin pain from those without this pain.

The presence of the secondary cleft sign was also examined in 2 moderate quality studies ${ }^{37} 38$ and the data were pooled for this outcome measure (figure 10). Meta-analysis showed a strong association between the presence of the secondary cleft sign and hip/groin pain $\mathrm{OR}=638.8$ (82.9-4925.5). Indeed, there was an absence of this sign on pubic symphysis MRI examination of 170 athletic controls. These 2 studies provide moderate evidence that the presence of the secondary cleft sign differentiates athletes with and without hip/groin pain.

Other abnormalities were reported by 4 MRI studies. ${ }^{32} 373840$ However, inconsistent methods of reporting and analysis of these abnormalities precluded data synthesis.

One moderate quality cohort study investigated the radiological signs of femoroacetabular impingement (FAI). ${ }^{35}$ This study used MRI of the hip to determine whether higher $\alpha$ angles correlated with the presence of symptomatic hips. Athletes with symptomatic hips were found to have significantly higher $\alpha$ angles when measured at the 12, 1 and 2 o'clock positions (corresponding to the anterolateral head-neck junction) $(\mathrm{p}<0.022)$, but not at the $9,10,11$ or 3 o'clock positions $(p=0.181-0.602)$. This means that there is currently limited evidence that the radiological signs of FAI differentiate athletes with hip/groin pain from those without these symptoms.

\section{Other outcome measures}

Biomarkers of cartilage damage and inflammation circulating in the blood were examined in one high-quality study, ${ }^{52}$ Table 1. The biomarkers examined were cartilage oligomeric matrix protein (COMP) and $\mathrm{C}$ reactive protein (CRP). COMP is a connective tissue extracellular matrix protein that is a marker of cartilage turnover, and increased levels of COMP are associated with joint inflammation and OA. ${ }^{52} \mathrm{CRP}$ is another biological marker that is associated with inflammation. Athletes with symptomatic FAI had a $24 \%$ increase $(p=0.04)$ in circulating levels of COMP and a $276 \%$ increase $(p<0.001)$ in circulating levels of CRP. Therefore, there is limited evidence that the biomarkers for cartilage degradation and inflammation are elevated in athletic males with hip/groin pain compared to controls.

\section{DISCUSSION}

This review systematically identified factors for differentiating athletes with or without hip/groin pain. Of the 17 studies included for data synthesis, 10 were of high quality, 6 moderate and 1 low quality. A total of 62 variables were examined, with meta-analysis performed for 8 of these variables. There is strong evidence that the following variables differentiate athletes with hip/groin pain from those without: PROs, pain on adductor squeeze test, hip IR, bent knee fall out, adductor squeeze strength, and trunk muscle function. Hip IR range of motion measured in flexion differentiates painful athletes with a larger effect size than when hip IR is measured in neutral. There is moderate evidence that the presence of pubic symphysis bone oedema and the secondary cleft sign are more common in athletes with hip/groin pain. There is limited evidence that hip ER measured in flexion differentiates between athletes with and without hip/groin pain, and strong evidence that this movement did not differ when measured in neutral. The low number of studies comparing athletes with hip/groin pain to those without hip/groin pain, using the following outcome measures: pain provocation tests (apart from the squeeze test), X-ray abnormalities of the pubic symphysis, radiological features of FAI, and biomarkers of cartilage degradation, means that currently there is only limited evidence supporting the association of these outcome measures with the presence of hip/groin pain. The findings of this review do not, however, indicate how well each of the various clinical and radiological tests can determine the presence of individual diagnostic categories.

The PROs used in the included studies were inconsistent, precluding meta-analysis. Furthermore, in some case-control studies, PROs were used to exclude symptomatic athletes from control groups. ${ }^{30} 3136$ Impairments in PROs ranged from 0 to $55 \%$, suggesting that further cross-sectional and cohort studies should use valid, reliable and consistent PROs to enable comparisons between studies.

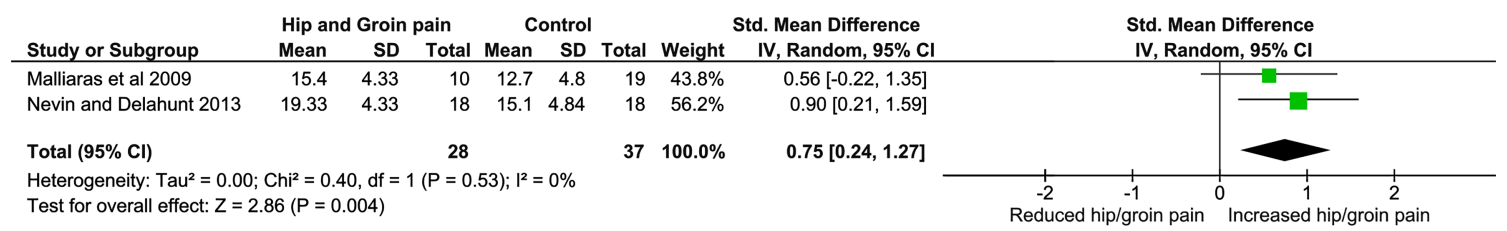

Figure 6 Forest plot: association between hip/groin pain and bent knee fall out range of motion. 


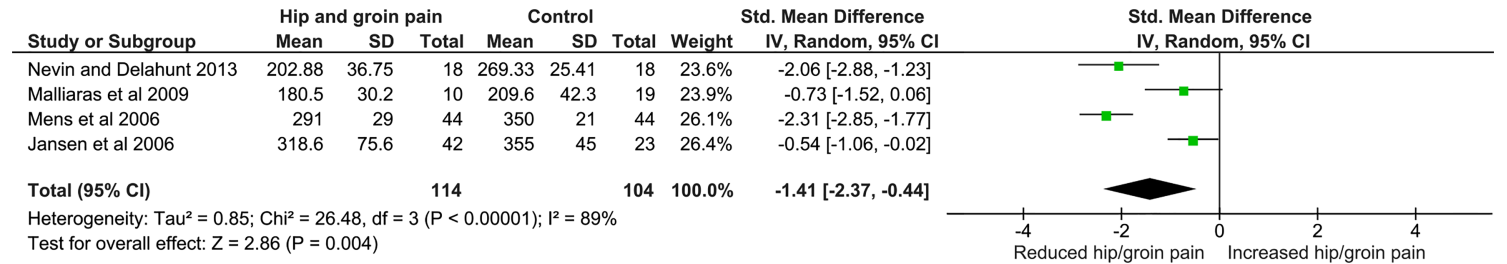

Figure 7 Forest plot: association between hip/groin pain and strength score for the adductor squeeze test.

Pain provocation tests are used clinically to diagnose hip/groin pain, and commonly to determine inclusion and exclusion criteria in research studies. This makes examining their ability to differentiate somewhat artificial in cases where assignment to case or control group has used pain provocation tests. We found one high-quality study that compared the ability of various pain provocation tests, conducted by a blinded assessor, to differentiate athletes with and without hip/groin pain. ${ }^{16}$ Another highquality cohort study ${ }^{53}$ examined pain on the adductor squeeze test, making meta-analysis possible for this test only. An OR of $4.31(1.86-10)$ was found on meta-analysis, providing strong evidence, with a large effect size, that pain on the adductor squeeze test differentiates athletes with and without current hip/ groin pain. The results of the meta-analysis do not, however, measure the validity of this test to diagnose any specific individual entity of groin pain. The lack of studies that met the inclusion criteria for this review means that only limited evidence exists for the diagnostic potential of the single adductor, bilateral adductor, active straight leg raise, pelvic belt, and impingement tests to differentiate athletes with groin pain.

Hip IR measured in $90^{\circ}$ flexion was examined in two moderate quality studies. ${ }^{33}$ Meta-analysis found moderate evidence, with a moderate effect size, that this movement is less in athletes with hip/groin pain; $\mathrm{SMD}=0.58(0.14-1.01)$. There was strong evidence, with a small effect size, that IR measured in neutral flexion/extension differentiates these groups; SMD $=0.42(0.01-$ 0.83). The actual difference between groups for both these movements was 3.8 and $3.7^{\circ}$, respectively, which approximates the reported measurement error. ${ }^{15}$ The association between a loss of hip IR and hip/groin pain has been proposed ${ }^{54-56}$ previously, with several possible mechanisms discussed. Bony impingement is one plausible mechanism and this review provides some support for this mechanism with one cohort study in which the symptomatic group had clinical and radiological features of FAI. ${ }^{35}$ The reduced hip range of motion associated with athletic groin pain has also been proposed to result from pain, muscle spasm, or capsular scarring. ${ }^{22} 55$

There was conflicting evidence for hip ER; limited evidence that ER measured in $90^{\circ}$ hip flexion does discriminate and strong evidence that ER measured in neutral flexion/extension does not discriminate between athletes with and without hip/ groin pain. It has been suggested that the neutral position of the hip is more reflective of the functional position for the demands of football. ${ }^{15}$ The findings of our review suggest that measuring IR and ER in hip flexion may have greater clinical utility in the management of hip/groin pain.

The BKFO test has good intratester and intertester reliability with a measurement error of $2-3 \mathrm{~cm} .{ }^{15}$ Meta-analysis of 2 highquality case-control studies ${ }^{5} 15$ found that hip/groin pain athletes had lower range of motion in this test by $3.6 \mathrm{~cm}$ $(1.3-5.8 \mathrm{~cm})$, supporting its clinical utility. The predictive ability of the BKFO test for the development of hip/groin pain has not been examined and prospective cohort research is recommended.

Hip adduction strength is considered important in hip/groin pain, and lower scores on the adductor squeeze test at $45^{\circ}$ hip flexion were observed in hip/groin pain athletes in a meta-analysis of four high-quality case-control studies. 5153036 The magnitude of the difference between the pain/no pain groups varied between the studies and there was high statistical heterogeneity which cannot easily be explained. It is unlikely to be due to the differing tools of measurement (sphygmomanometer and hand-held dynamometer), as the studies with the most similar results used one of each tool. The age, duration of symptoms, sport played and diagnostic criteria were also similar between studies. Therefore, although the heterogeneity is unexplained, each study and the overall pooled result confirm the clinical utility of the adductor squeeze test. Lower adductor squeeze test values have been shown to precede the onset of

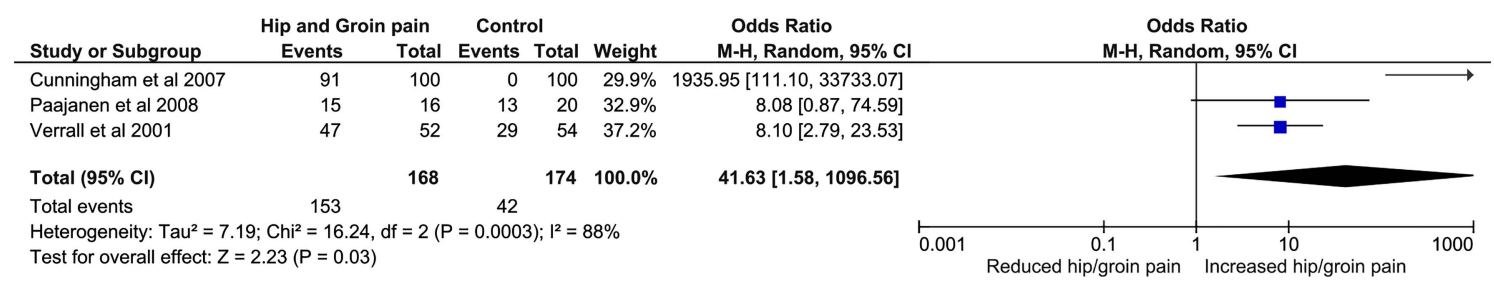

Figure 8 Forest plot: association between hip/groin pain and presence of bone oedema on MRI.

\begin{tabular}{|c|c|c|c|c|c|c|c|c|c|}
\hline \multirow{3}{*}{$\begin{array}{l}\text { Study or Subgroup } \\
\text { Paajanen et al } 2008 \\
\text { Verrall et al } 2001\end{array}$} & $\begin{array}{l}\text { Hip and G } \\
\text { Events }\end{array}$ & $\begin{array}{l}\text { pain } \\
\text { Total }\end{array}$ & Control & $\begin{array}{l}\text { ol } \\
\text { Total }\end{array}$ & Weight & $\begin{array}{c}\text { Odds Ratio } \\
\text { M-H, Random, } 95 \% \mathrm{Cl}\end{array}$ & \multicolumn{2}{|c|}{$\begin{array}{c}\text { Odds Ratio } \\
\text { M-H, Random, } 95 \% \mathrm{CI}\end{array}$} & \\
\hline & 15 & 16 & 13 & 20 & $18.7 \%$ & $8.08[0.87,74.59]$ & & & \\
\hline & 47 & 52 & 29 & 54 & $81.3 \%$ & $8.10[2.79,23.53]$ & & & \\
\hline Total $(95 \% \mathrm{Cl})$ & & 68 & & 74 & $100.0 \%$ & $8.10[3.10,21.17]$ & & & \\
\hline Total events & 62 & & 42 & & & & & & \\
\hline $\begin{array}{l}\text { Heterogeneity: } \text { Tau }^{2}= \\
\text { Test for overall effect: }\end{array}$ & $\begin{array}{l}.00 ; \mathrm{Chi}^{2}=\mathrm{C} \\
=4.27(\mathrm{P}<\end{array}$ & $\begin{array}{l}d f=1 \\
01)\end{array}$ & $(P=1.00$ & $; 1^{2}=0$ & & 0.001 & 0.1 & 10 & 1000 \\
\hline
\end{tabular}

Figure 9 Forest plot: association between hip/groin pain and presence of bone oedema on MRI following sensitivity analysis. 


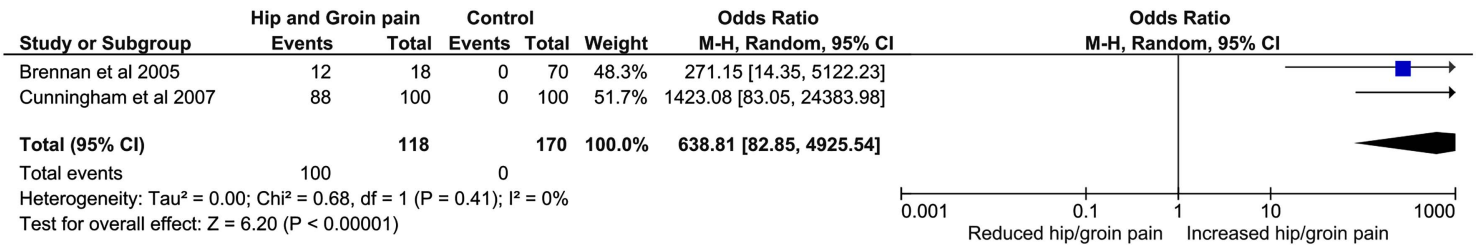

Figure 10 Forest plot: association between hip/groin pain and presence of secondary cleft sign.

groin pain in a small study of Australian rules footballers, ${ }^{57}$ but this finding is yet to be tested in other populations. The measurement of adductor squeeze strength is, therefore, recommended in the screening for hip/groin pain in athletes and also to monitor the treatment response in athletes with current hip/ groin pain.

In single studies, other strength measures (isokinetic hip extension, adduction and abduction, isometric hip abduction) did not differentiate between hip/groin pain athletes and controls. ${ }^{15} 51$ There is limited evidence that hip flexion and hip flexion/extension ratio did differentiate, with higher hip flexion strength found in the hip/groin pain group. ${ }^{51}$ Prospective studies using varying methods of measurement have identified lower adduction strength as predictive of athletes who develop hip/groin pain. ${ }^{3} 212326$ Our systematic review, therefore, suggests that further investigation with reliable, valid and consistent measurement methods and instruments is required to determine which measures of strength, apart from the adductor squeeze test, differentiate athletes with and without hip/groin pain.

Trunk muscle function was examined in three high-quality case-control studies ${ }^{30} 3150$ using diverse measurement methods, table 1. Different aspects of trunk muscle function were evaluated: onset timing of the abdominals, eccentric and concentric abdominal and back strength, and abdominal muscle bulk at rest and with activity. These studies provide strong evidence that trunk muscle function is altered in hip/groin pain athletes and we suggest that it should be assessed and addressed in management. A randomised controlled trial of an exercise programme that included exercises aimed to improve trunk muscle function has also been shown to be successful for the management of long-standing groin pain. ${ }^{58} 59$ The cross-sectional nature of the included studies means that it is unknown whether the altered trunk muscle function precedes or results from hip/groin pain. Future prospective studies can examine this question.

Only one low quality study of pubic symphysis X-ray was included in our review. ${ }^{39}$ This study found more abnormalities in the hip/groin pain athletes. However, there was no information available on the activity type or level in the controls, and a previous study found higher activity levels to be associated with a greater incidence of X-ray abnormalities. ${ }^{60}$ It is possible that the observed abnormalities are a result of activity rather than related to the presence of hip/groin pain. Therefore, there was limited evidence to indicate that pubic symphysis X-ray differs in athletes with hip/groin pain compared to athletic controls. The utility for diagnosis and management of hip/groin pain in the athlete is not yet established.

We found moderate evidence that pubic bone oedema differentiates athletes with hip/groin pain from those without pain. However, a prospective study of 19 elite junior soccer players found pubic bone marrow oedema in 13 asymptomatic players at baseline. ${ }^{34}$ One retrospective study in this review found no bone oedema in 100 controls, ${ }^{38}$ including 50 soccer players. The absence of bone oedema in the 50 soccer player controls contradicts other studies of asymptomatic footballers in which $54-72 \%$ had oedema. ${ }^{32} 3440$ Similarly, there was moderate evidence that the presence of a secondary cleft sign differentiates hip/groin pain athletes from athletes without pain, with an absence of this sign in 170 asymptomatic control subjects. ${ }^{37} 38$ It is worth noting that both these studies were from the same clinic and may contain the same data set of MRI, thus potentially influencing these findings. Our review found moderate evidence that the presence of bone oedema and the secondary cleft sign on MRI can differentiate athletes with and without hip and groin pain. However, research with more rigorous methodology is required to better understand the clinical and prognostic significance of these findings. A recent review of the radiological findings in athletic groin pain also found that methodological quality was lacking and a systematic approach was needed in future research. ${ }^{61}$

The presence of radiological signs of FAI in athletes was examined in one moderate quality study ${ }^{35}$ providing limited evidence that these signs can differentiate athletes with hip/groin pain. There are many studies suggesting that the radiological features of FAI are highly prevalent in athletic populations, ${ }^{41} 42$ 62-64 and in athletes with hip/groin pain. ${ }^{65} 66$ However, case-control, cross-sectional and prospective studies that examine FAI in athletes are lacking. There are many unanswered questions regarding the relationship between radiological and clinical signs of FAI in athletes, and how these relate to the development of hip/groin pain. Further research in welldescribed groups is required to answer these questions.

\section{Limitations}

This systematic review used strict predefined inclusion criteria; therefore, some studies in the field were not included due to either low subject numbers or use of non-athletic controls. The search strategy was comprehensive and included six languages; however some studies may still have been missed with this strategy. The results of this review are also limited by the current state of the literature, with inconsistent methods of measurement used in the assessment, management and prevention of hip/groin pain in athletes. The current lack of cohort studies with large participant numbers also limits the quality of the data available for synthesis in this review. Most of the athletes included had chronic groin pain and therefore, the generalisability of these findings to athletes with acute groin pain is unknown. Furthermore, the low number of female participants included in the studies potentially limits the applicability of the findings of this review to female athletes. Only 7 included studies used blinded assessors, suggesting a potential for bias in many of the studies. It is recommended that future research include blinded assessors and female participants where possible.

\section{CONCLUSIONS}

This systematic review identified and synthesised data from 17 studies, of which 10 were high quality. The following levels of 
evidence were found for various factors able to differentiate athletes with and without hip/groin pain. Strong evidence for: PROs, pain on the adductor squeeze test, hip IR, bent knee fall out, adductor squeeze strength and altered trunk muscle function. Moderate evidence for: pubic bone oedema, secondary cleft sign. Limited evidence for: pain provocation tests (other than the adductor squeeze), hip ER in $90^{\circ}$ flexion, X-ray abnormalities of the pubis, radiological features of FAI and biomarkers of cartilage degradation. There is strong evidence that hip ER range of motion does not differentiate between these athletes when measured in neutral flexion/extension.

PROs, pain and reduced strength on the adductor squeeze test, reduced range of motion in internal rotation and bent knee fall out are the outcome measures that best differentiate athletes with hip/groin pain from those without pain.

\section{What are the new findings?}

There is strong evidence that the following factors differentiate athletes with hip/groin pain from those without:

- Patient-reported outcomes

- Presence of pain on the adductor squeeze test

- Reduced strength score on adductor squeeze test

- Reduced range of motion in hip internal rotation and bent knee fall out

- Altered trunk muscle function.

There is moderate evidence that the following factors

differentiate athletes with hip/groin pain from those without:

- Presence of pubic bone oedema and secondary cleft sign on MRI.

\section{How might this review impact on clinical practice in the} near future?

- Provides clinicians with an overview of how well measures commonly used in the screening, assessment and management of athletes differentiate between those with and without hip/groin pain.

- Summarises the literature on radiological measures of relevance to hip/groin pain in athletes.

Acknowledgements The authors would like to thank Wichor Bramer for his assistance with the literature search for this study.

Contributors ABM, RA, AW and KMC planned the manuscript. All authors contributed to the interpretation of the data, writing, editing and approval of the manuscript.

Competing interests None declared.

Provenance and peer review Not commissioned; externally peer reviewed.

Open Access This is an Open Access article distributed in accordance with the Creative Commons Attribution Non Commercial (CC BY-NC 4.0) license, which permits others to distribute, remix, adapt, build upon this work non-commercially, and license their derivative works on different terms, provided the original work is properly cited and the use is non-commercial. See: http://creativecommons.org/ licenses/by-nc/4.0/

\section{REFERENCES}

1 Orchard J, Seward H. Epidemiology of injuries in the Australian Football League, seasons 1997-2000. Br J Sports Med 2002;36:39-44.
2 Werner J, Hagglund $M$, Walden $M$, et al. UEFA injury study: a prospective study of hip and groin injuries in professional football over seven consecutive seasons. Br J Sports Med 2009;43:1036-40.

3 O'Connor DM. Groin injuries in professional rugby league players: a prospective study. J Sports Sci 2004;22:629-36.

4 Ryan J, DeBurca N, Mc Creesh K. Risk factors for groin/hip injuries in field-based sports: a systematic review. Br J Sports Med 2014;48:1089-96.

5 Nevin $F$, Delahunt E. Adductor squeeze test values and hip joint range of motion in Gaelic football athletes with longstanding groin pain. J Sci Med Sport 2014:17:155-9.

6 Feeley BT, Powell JW, Muller MS, et al. Hip injuries and labral tears in the National Football League. Am J Sports Med 2008;36:2187-95.

7 Emery CA, Meeuwisse WH. Risk factors for groin injuries in hockey. Med Sci Sports Exerc 2001;33:1423-33.

8 Thorborg K, Hölmich P. Advancing hip and groin injury management: from eminence to evidence. Br J Sports Med 2013;47:602-5.

9 Bradshaw CJ, Bundy M, Falvey E. The diagnosis of longstanding groin pain: a prospective clinical cohort study. Br J Sports Med 2008;42:551-4.

10 Caudill $\mathrm{P}$, Nyland J, Smith $\mathrm{C}$, et al. Sports hernias: a systematic literature review. Br J Sports Med 2007;42:954-64.

11 Holmich P, Renstrom PA. Long-standing groin pain in sportspeople falls into three primary patterns, a "clinical entity" approach: a prospective study of 207 patients* COMMENTARY. Br J Sports Med 2007;41:247-52.

12 Hegedus EJ, Stern B, Reiman MP, et al. A suggested model for physical examination and conservative treatment of athletic pubalgia. Phys Ther Sport 2013;14:3-16.

13 Falvey EC, Franklyn-Miller A, McCrory PR. The groin triangle: a patho-anatomical approach to the diagnosis of chronic groin pain in athletes. Br J Sports Med 2009:43:213-20

14 Holmich P. Clinical examination of athletes with groin pain: an intraobserver and interobserver reliability study. Br J Sports Med 2004;38:446-51.

15 Malliaras P, Hogan A, Nawrocki A, et al. Hip flexibility and strength measures: reliability and association with athletic groin pain. Br J Sports Med 2009;43:739-44.

16 Verrall GM, Slavotinek JP, Barnes PG, et al. Description of pain provocation tests used for the diagnosis of sports-related chronic groin pain: relationship of tests to defined clinical (pain and tenderness) and MRI (pubic bone marrow oedema) criteria. Scand J Med Sci Sports 2005;15:36-42.

17 Engebretsen $\mathrm{AH}$, Myklebust $\mathrm{G}$, Holme I, et al. Intrinsic risk factors for groin injuries among male soccer players: a prospective cohort study. Am J Sports Med 2010;38:2051-7

18 Verrall GM, Slavotinek JP, Barnes PG, et al. Hip joint range of motion restriction precedes athletic chronic groin injury. I Sci Med Sport 2007;10:463-6.

19 Crow JF, Pearce AJ, Veale JP, et al. Hip adductor muscle strength is reduced preceding and during the onset of groin pain in elite junior Australian football players. J Sci Med Sport 2010;13:202-4.

20 Witvrouw E, Danneels L, Asselman $P$, et al. Muscle flexibility as a risk factor for developing muscle injuries in male professional soccer players a prospective study. Am J Sports Med 2003;31:41-6.

21 Tyler TF, Nicholas SJ, Campbell RJ, et al. The association of hip strength and flexibility with the incidence of adductor muscle strains in professional ice hockey players. Am J Sports Med 2001;29:124-8.

22 Ibrahim A, Murrell GA, Knapman P. Adductor strain and hip range of movement in male professional soccer players. J Orthop Surg Hong Kong 2007;15:46-9.

23 Arnason A. Risk Factors for Injuries in Football. Am J Sports Med 2004:32:5S-16.

24 Maffey L, Emery C. What are the risk factors for groin strain injury in sport? Sports Med 2007:37:881-94.

25 Tyler TF, Nicholas SJ, Campbell RJ, et al. The effectiveness of a preseason exercise program to prevent adductor muscle strains in professional ice hockey players. Am J Sports Med 2002;30:680-3.

26 Engebretsen AH, Myklebust G, Holme I, et al. Prevention of injuries among male soccer players: a prospective, randomized intervention study targeting players with previous injuries or reduced function. Am J Sports Med 2008;36:1052-60.

27 Junge $A$, Rösch $D$, Peterson $L$, et al. Prevention of soccer injuries: a prospective intervention study in youth amateur players. Am J Sports Med 2002;30:652-9.

28 Hölmich P, Larsen K, Krogsgaard K, et al. Exercise program for prevention of groin pain in football players: a cluster-randomized trial: Exercise program for prevention of groin pain in football players. Scand J Med Sci Sports 2010;20:814-21.

29 Thorborg K, Holmich P, Christensen R, et al. The Copenhagen Hip and Groin Outcome Score (HAGOS): development and validation according to the COSMIN checklist. Br J Sports Med 2011;45:478-91.

30 Jansen J, Weir A, Dénis $R$, et al. Resting thickness of transversus abdominis is decreased in athletes with longstanding adduction-related groin pain. Man Ther 2010;15:200-5.

31 Cowan SM, Schache AG, Brukner $P$, et al. Delayed onset of transversus abdominus in long-standing groin pain. Med Sci Sports Exerc 2004;36:2040-5.

32 Verrall GM, Slavotinek JP, Fon GT. Incidence of pubic bone marrow oedema in Australian rules football players: relation to groin pain. $\mathrm{Br}$ I Sports Med 2001;35:28-33. 
33 Verrall GM, Hamilton IA, Slavotinek JP, et al. Hip joint range of motion reduction in sports-related chronic groin injury diagnosed as pubic bone stress injury. J Sci Med Sport 2005;8:77-84.

34 Lovell G, Galloway H, Hopkins W, et al. Osteitis pubis and assessment of bone marrow edema at the pubic symphysis with MRI in an elite junior male soccer squad. Clin J Sport Med 2006;16:117-22.

35 Siebenrock KA, Kaschka I, Frauchiger L, et al. Prevalence of cam-type deformity and hip pain in elite ice hockey players before and after the end of growth. Am J Sports Med 2013;41:2308-13.

36 Mens J, Inklaar H, Koes BW, et al. A new view on adduction-related groin pain. Clin J Sport Med 2006;16:15-19.

37 Brennan D, O'Connell MJ, Ryan M, et al. Secondary cleft sign as a marker of injury in athletes with groin pain: MR image appearance and interpretation1. Radiology 2005;235:162-7.

38 Cunningham PM, Brennan D, O'Connell M, et al. Patterns of bone and soft-tissue injury at the symphysis pubis in soccer players: observations at MRI. Am J Roentgenol 2007;188:W291-6.

39 Besjakov J, von Scheele C, Ekberg 0, et al. Grading scale of radiographic findings in the public bone and symphysis in athletes. Acta Radiol 2003;44:79-83.

40 Paajanen $\mathrm{H}$, Hermunen $\mathrm{H}$, Karonen J. Pubic magnetic resonance imaging findings in surgically and conservatively treated athletes with osteitis pubis compared to asymptomatic athletes during heavy training. Am J Sports Med 2007;36:117-21.

41 Mariconda M, Cozzolino A, Pietto F, et al. Radiographic findings of femoroacetabular impingement in capoeira players. Knee Surg Sports Traumatol Arthrosc 2014;22:874-81.

42 Larson CM, Sikka RS, Sardelli MC, et al. Increasing alpha angle is predictive of athletic-related "Hip" and "Groin" pain in collegiate National Football League prospects. Arthrosc J Arthrosc Relat Surg 2013;29:405-10.

43 Downs SH, Black N. The feasibility of creating a checklist for the assessment of the methodological quality both of randomised and non-randomised studies of health care interventions. J Epidemiol Community Health 1998;52:377-84.

44 Irving DB, Cook JL, Menz HB. Factors associated with chronic plantar heel pain: a systematic review. J Sci Med Sport 2006;9:11-22.

45 Munn J, Sullivan SJ, Schneiders AG. Evidence of sensorimotor deficits in functional ankle instability: a systematic review with meta-analysis. J Sci Med Sport 2010;13:2-12.

46 Cohen J. Statistical power analysis for the behavioral sciences.2nd edn. Hillsdale, NJ, USA: Lawrence Erlbaum Associates, 1988.

47 Coombes BK, Bisset L, Vicenzino B. Efficacy and safety of corticosteroid injections and other injections for management of tendinopathy: a systematic review of randomised controlled trials. Lancet 2010;376:1751-67.

48 Van Tulder M, Furlan A, Bombardier C, et al. Updated method guidelines for systematic reviews in the Cochrane Collaboration Back Review Group. Spine 2003;28:1290-9.
49 Jansen JACG, Mens JMA, Backx FJG, et al. Diagnostics in athletes with long-standing groin pain: diagnostics in athletes with groin pain. Scand J Med Sci Sports 2008;18:679-90.

50 Sayed Mohammad W, Ragaa Abdelraouf 0, Abdel-aziem AA. Concentric and eccentric strength of trunk muscles in osteitis pubis soccer players. J Back Musculoskelet Rehabil 2014;27:147-52.

51 Mohammad WS, Abdelraouf OR, Elhafez SM, et al. Isokinetic imbalance of hip muscles in soccer players with osteitis pubis. J Sports Sci 2014;32:934-9.

52 Bedi A, Lynch EB, Sibilsky Enselman ER, et al. Elevation in circulating biomarkers of cartilage damage and inflammation in athletes with femoroacetabular impingement. Am J Sports Med 2013;41:2585-90.

53 Taylor CJ, Pizzari T, Ames N, et al. Groin pain and hip range of motion is different in indigenous compared to non-indigenous young Australian football players. I Sci Med Sport 2011;14:283-6.

54 Williams JG. Limitation of hip joint movement as a factor in traumatic osteitis pubis. Br J Sports Med 1978;12:129-33.

55 Fricker PA, Taunton JE, Ammann W. Osteitis pubis in athletes. Sports Med 1991;12:266-79.

56 Philippon MJ, Maxwell RB, Johnston TL, et al. Clinical presentation of femoroacetabular impingement. Knee Surg Sports Traumatol Arthrosc 2007;15:1041-7.

57 Crowe RJ. A comparative study of the results of surgery on the sporting groin. I Sci Med Sport 1999;2:97.

58 Hölmich $\mathrm{P}$, Uhrskou $\mathrm{P}$, Ulnits $\mathrm{L}$, et al. Effectiveness of active physical training as treatment for long-standing adductor-related groin pain in athletes: randomised trial. Lancet 1999;353:439-43.

59 Holmich P, Nyvold P, Larsen K. Continued significant effect of physical training as treatment for overuse injury: 8- to 12-year outcome of a randomized clinical trial. Am J Sports Med 2011;39:2447-51.

60 Harris NH, Murray RO. Lesions of the symphysis in athletes. Br Med J 1974;4:211.

61 Branci S, Thorborg K, Nielsen MB, et al. Radiological findings in symphyseal and adductor-related groin pain in athletes: a critical review of the literature. $\mathrm{Br} J$ Sports Med 2013;47:611-19.

62 Agricola R, Bessems JHJM, Ginai AZ, et al. The development of cam-type deformity in adolescent and young male soccer players. Am J Sports Med 2012;40:1099-106.

63 Johnson AC, Shaman MA, Ryan TG. Femoroacetabular Impingement in Former High-Level Youth Soccer Players. Am J Sports Med 2012;40:1342-6.

64 Gerhardt MB, Romero AA, Silvers $\mathrm{HJ}$, et al. The prevalence of radiographic hip abnormalities in elite soccer players. Am J Sports Med 2012;40:584-8.

65 Weir A, de Vos RJ, Moen M, et al. Prevalence of radiological signs of femoroacetabular impingement in patients presenting with long-standing adductor-related groin pain. Br J Sports Med 2009;45:6-9.

66 Holmich P, Thorborg K, Nyvold P, et al. Does bony hip morphology affect the outcome of treatment for patients with adductor-related groin pain? Outcome 10 years after baseline assessment. Br J Sports Med 2014;48:1240-4. 